\title{
Developing Dynamic Conflict Resolution Models Based on the Interpretation of Personal Conflict Styles
}

\author{
Davide Carneiro, Marco Gomes, Paulo Novais, José Neves \\ Department of Informatics, University of Minho, Braga, Portugal \\ dcarneiro@di.uminho.pt,pg18373@alunos.uminho.pt, \{pjon, jneves\}@di.uminho.pt
}

\begin{abstract}
Conflict resolution is a classic field of Social Science research. However, with conflicts now also emerging in virtual environments, a new field of research has been developing in which Artificial Intelligence and particularly Ambient Intelligence are interesting. As result, the field of Online Dispute Resolution emerged as the use (in part or entirely) of technological tools to solve disputes. In this paper we focus on developing conflict resolution models that are able to adapt strategies in real time according to changes in the personal conflict styles of the parties. To do it we follow a novel approach in which an intelligent environment supports the lifecycle of the conflict resolution model with the provision of important context knowledge. The presented framework is able to react to important changes in the context of interaction, resulting in a conflict resolution approach that is able to perceive the parties and consequently achieve better outcomes.
\end{abstract}

Keywords: Online Dispute Resolution, Intelligent Environments, Conflict Styles, Profiling.

\section{Introduction}

The topic of conflict resolution is a quite classic and old one, as old as conflicts themselves. Conflicts are natural and emerge as a consequence of our complex society, in which individuals focus on the maximization of the own gain, sometimes disregarding the other's rights. A conflict can be seen as an opposition of interests or values which, in a certain way, disturbs or blocks an action or a decision making process. Consequently, in order for the action to be carried out, the conflict has to be solved first [1]. The concept of conflict and its resolution has traditionally been addressed by Social Science, although in the last decades Information Science also stepped in. The intersection of these two fields is of great interest as it combines all the established theory about conflict resolution with new methodologies and support tools.

Moreover, we must consider that nowadays most of the conflicts are generated in virtual settings, most of the times supported by an electronic contract. However, very few tools exist to settle conflicts inside their context. As a consequence, conflicting parties have to resort to traditional conflict resolution methods, throwing away significant advantages of the technological environments. The use of technology to develop tools that can support the conflict resolution process, together with the 
creation of virtual environments for that purpose, is thus of interest. Moreover, Pitt et al. address the issue of the costs of conflicts and the need for alternatives to traditional litigation in court [2]. In particular, the authors argue that litigation is a slow and costly process which may have a special impact on the business of companies and governments. The potential for appeals also adds to the amount of delay and cost.

The work described in this paper is framed in this context. Specifically, after analyzing the current state of the art of conflict resolution platforms, we concluded that most of the processes are static and make no use of context information. In that sense, we are developing a new approach, in line with the concept of Ambient Intelligence. Our aim is to develop conflict resolution methods that make use of context information to adapt strategies in real time, in order to more efficiently achieve satisfactory outcomes. This information may include the conflict style of the parties, the level of escalation, their attitude or even the emotional state. In order to implement a framework able to encompass this kind of information, we are following an approach in line with the concept of Intelligent Environments, in which an intelligent environment supports the conflict resolution platform with context information, as envisioned by [3]. In this work we take into consideration the work of Lewiki et al. [5] and Goldberg et al. [6] on the dynamics and processes of conflict resolution, and the work of Raiffa [7] on decision theory and negotiation analysis.

\subsection{Alternative Dispute Resolution}

Alternative Dispute Resolution refers to mechanisms that aim to solve disputes without recurring to the traditional judicial process, i.e. litigation in courts. This already traditional approach includes mechanisms such as negotiation, mediation or arbitration. Online Dispute Resolution (ODR) [4], on the other hand, refers to the use of these mechanisms in a technological context, either supported by technology or under a virtual computational environment.

Negotiation [7] is a collaborative and informal process by means of which parties communicate and, without external influence, try to achieve an outcome that can satisfy both. Negotiation is widely used in the most different fields, including legal proceedings, divorces, parental disputes or even hostage situations. From the perspective of Walton and McKersie [8], negotiation can be classified as being distributive or integrative, being integrative negotiation more desirable than distributive. Another collaborative form of conflict resolution is mediation [9]. Here, parties in dispute are guided by a $3^{\text {rd }}$ neutral and independent entity who tries to guide the process to an outcome that may satisfy both disputing parties. In this approach, as in negotiation, parties decide about the outcome instead of it being imposed by the nonaligned one, although using its assistance. The nonaligned is chosen by the parties and has no authority for deciding on the outcome of the dispute but only for guiding and assisting them throughout it. Finally, we can also mention arbitration [10], a method in which the two parties also use the help of a $3^{\text {rd }}$ independent and neutral entity for solving a dispute but. However, this entity has no active role on helping the parties throughout the whole process. Instead, the arbitrator simply hears the parties and, based on the facts presented, takes a decision without influencing the parties during their presentations. Traditionally, the outcome of an arbitration process is 
binding, i.e., there is a final enforceable award that the parties will respect. However, arbitration can also be non-binding.

With the technological evolution new needs appeared in the field of conflict resolution, especially due to the new forms of dispute caused essentially by electronic contracting. New ways to solve disputes are hence appearing, so that the disputant parties neither need to travel nor to meet in courtrooms or in front of arbitrators or mediators. Different forms or methods of alternative dispute resolution for electronic environments have been pointed out by legal doctrine. As a result, we can now speak of Online Dispute Resolution as any method of dispute resolution in which wholly or partially an open or closed network is used as a virtual location to solve a dispute [4].

From a technological point of view, a relevant issue is to determine in what way and to what point traditional mechanisms can be transplanted or adapted to the new telematic environments, taking advantage of all the resources made available by the newest information and communication technologies, namely Artificial Intelligence models and techniques that include but are not limited to Argumentation, Game Theory, Heuristics, Intelligent Agents and Group Decision Systems, as described by Peruginelli and Chiti [11] and Lodder and Thiessen [12]. Moreover, contrary to previous approaches, in Online Dispute Resolution it must be considered not only the disputant parties and the eventual third party but also what Ethan Katsh and Janet Rifkin call the fourth party, i.e., the technological elements involved.

The ultimate goal of AI research in this field is to accomplish a technological threshold, resulting in computational systems that are indeed the $3^{\text {rd }}$ party. In this sweeping approach, there is no major human intervention on the outcome or in guiding the parties to a specific situation. There is, on the other hand, a computational system that performs that major role. This is usually known as an electronic mediator or arbitrator. This is evidently the most challenging approach to follow as computational systems that implement the cognitive capabilities of a Human expert are not easy to accomplish, especially if we include the ability to perceive the emotions and desires of the parties involved.

Depending on the importance of the role that computer systems play on ODR systems, they can be categorized as first or second generation [11]. While in first generation ODR systems technology is a mere tool and has no autonomy, second generation ODR systems are essentially defined by a more autonomous and effective use of technical tools. For the implementation of such services, one can look at fields as diverse as Artificial Intelligence, Mathematics or Philosophy. In the intersection of these fields one can find a range of technologies that will significantly empower the previous generation of ODR tools, namely Artificial Neural Networks, software agents, Case-based Reasoning mechanisms, methods for Knowledge Representation and Reasoning, Argumentation, Learning, and Negotiation. Thus, we move forward from a paradigm in which reactive communication tools are used by parties to share information, to an immersive intelligent environment [3] which proactively supports the lifecycle of the conflict resolution mechanism with important knowledge.

\subsection{Important Knowledge}

The ideal dispute resolution process is one in which the two parties are better at the 
end than they were at the beginning. Unfortunately, not all disputes have such conclusion. In order to improve this, we believe that it is of ultimate importance to: (1) provide the parties with important knowledge about the dispute and (2) potentiate the role of the parties throughout all the process. In fact, parties that have poor access to important information generally make bad choices or, at least, they hardly make the best ones.

An important step on the development of conflict resolution mechanisms is thus to identify the knowledge that is meaningful for the parties, according to the legal domain of the dispute. In a first instance, it would be interesting for a party to determine to which extent is it reasonable to engage in a dispute resolution process. That is, are there any significant advantages against litigation? This question can be analyzed from several points of view. On the one hand, alternative dispute resolution processes are generally faster, cheaper, more private and personalized [9]. There is however another important factor: the possible outcome reached through each of the processes. That is, will I reach a better outcome using an alternative dispute resolution process instead of litigation?

It would be really important for each party to know its BATNA - Best Alternative to a Negotiated Agreement, or the possible best outcome "along a particular path if I try to get my interests satisfied in a way that does not require negotiation with the other party" [13]. A party should then understand the notion of a BATNA and what role it should play in ODR. Doing so will, at least, contribute to the acknowledgement that an agreement may be disadvantageous [14]. In fact, the position of the parties may become much more unclear if they are not foreseeing the possible results in case the negotiation / mediation fails. As stated by [6], if you are unaware of what results you could obtain if the negotiations are unsuccessful, you run the risk of entering into an agreement that you would be better off rejecting or rejecting an agreement that you would be better off entering into. That is to say, the parties, by determining their BATNA, would on one side become better protected against agreements that should be rejected and, on the other side, be in a better condition to reach an agreement that better satisfy their interests [15]. But, besides that, a BATNA may play additional interesting features for the parties. For instance, it may be used as a way to put pressure on the other party, especially in dispute resolution procedures allowing the choice of going to court [15].

However, the use of the BATNA alone is not enough to take informed decisions as parties often tend to develop an overly optimistic view on their chances in disputes [15]. This may lead parties to calculate unrealistic BATNAs, which will influence later decisions, leading them reject generous offers from the other parties or to stand stubbornly fixed in some unrealistic positions [15]. It is thus important to also consider the other side of the coin, embodied by the concept of WATNA, or the Worst Alternative to a Negotiated Agreement [13, 16, 17]. A WATNA intends to estimate the worst possible outcome along a litigation path. It can be important in the calculation of the real risks that parties will face in a judicially determined litigation, imagining the worst possible outcome for the party. Considering both these concepts, a party would be aware of the best and worst scenario if the dispute is to be solved in a court.

This helps establish two important boundaries. However, it could also be interesting to consider the whole space between the BATNA and WATNA as a useful 
element to be taken into account before making or accepting proposals. Indeed, the less space there is between the BATNA and the WATNA, the less dangerous it becomes for the party not to accept the agreement (unless, of course, their BATNA is really disadvantageous). On the other hand, a wider space between the BATNA and the WATNA would usually mean that it can become rather dangerous for the party not to accept the ODR agreement (except in situations when the WATNA is really not inconvenient at all for the party). We can thus argue that the knowledge about the space between the BATNA and the WATNA is also very important. This space is evidently related to the Zone of Possible Agreement proposed by Raiffa [18].

More than that, it would also be interesting for a party to be aware of the region of this space in which an outcome is more likely. That is, if the parties are to solve the dispute through litigation, what is the most likely outcome? In fact, sticking only with the BATNA and WATNA may be unrealistic as these are usually not the most likely outcomes but merely informative boundary values. Thus, an informed party should also consider the MLATNA - Most Likely Alternative to a Negotiated Agreement [17]. Following the same line of thought, we can additionally state that the existence of metrics that measure the probability of each possible outcome could also be extremely useful for a party in an attempt to understand how likely each scenario is [22].

\section{Conflict Resolution Styles}

In alternative conflict resolution processes in which humans have a preponderant role, specifically in negotiation and mediation, the style of dealing with the conflict of each party will certainly influence the course of action and, consequently, the outcome. On the process of developing conflict resolution mechanisms one should thus regard personal conflict styles as key information. Kenneth Thomas and Ralph Kilmann formalized the way we respond to conflict situations into five different modes in terms of individual's assertiveness and cooperativeness [19]. In this context, assertiveness denotes the extent to which the person attempts to satisfy his/her own interests while cooperativeness denotes the extent to which the person attempts to satisfy the other person's interests. The conflict styles are:

- Competing - This is an uncooperative style by means of which an individual aims at maximizing his/her own gain at the other's expenses. This is a power-oriented style in which an individual will use whatever power seems appropriate to win his/her position (e.g. ability to argue, rank, economic sanctions);

- Accommodating - This style is the opposite of competing, i.e., it is cooperative. When an individual shows an accommodating behavior, he/she neglects his/her own gain to maximize the gain of the other. Under this behavior one founds an element of self-sacrifice. Accommodating includes well-known behaviors such as selfless generosity or charity, obeying another individual's order when we may prefer not to do so or accepting another's point of view; 
- Avoiding - The individual that shows an avoiding style of conflict tries to satisfy neither his/her own interests nor those of the other individual. It can be said that he/she is not dealing with the conflict. This style may be evidenced by behaviors such as diplomatically sidestepping an issue, postponing an issue until a better opportunity arises, or simply withdrawing from a threatening situation;

- Collaborating - This cooperative style is the complete opposite of avoiding. When an individual collaborates, he/she attempts to work with the other party to find some solution that fully satisfies the interests of both parties. In this process, the individual explores an issue to discover the underlying desires and fears of the two individuals. An individual that is collaborating might try to explore a disagreement to learn from other's insights;

- Compromising - When an individual has a compromising style of dealing with a conflict, he/she tries to find some expedient, mutually acceptable solution that can partially satisfy both parties. This style is somewhat an intermediate one between competing and accommodating. Generally, compromising can mean splitting the differences between the two positions, exchanging concessions, or seeking a quick middle-ground solution.

Whether it is because of past experiences or because of our temperament, each of us is capable of using all of these conflict-handling styles. Moreover, none of us can be characterized as having one single style of dealing with a conflict. Nevertheless, certain individuals rely on some modes more than others and, therefore tend to use them more often. From the point of view of a mediator and even from the point of view of a conflict resolution platform, it is important to determine the parties' conflict style in an attempt to define how each party will be affected by a given issue. Once the conflict styles are identified, strategies can be implemented that aim at improving the success rate of the conflict resolution process. Namely, we are interesting in developing dynamic processes that adapt strategies based on changes on the conflict styles of the parties. For instance, it is usual for parties to show an avoiding conflict style at the beginning of the process. However, they tend to gradually advance into a more cooperative style. When the conflict resolution platform detects these changes, it may start proposing more "audacious" outcomes since parties will more likely accept them.

\section{UMCourt}

The work described in this paper is being developed in the context of the TIARAC project - Telematics and Artificial Intelligence in Alternative Conflict Resolution. In that sense, a conflict resolution platform is being developed in which these ideas are being applied: the UMCourt. UMCourt is an agent-based conflict resolution platform that implements two high level functionalities. On the one hand, there is a significant focus on the building and provision of useful knowledge that allows both parties and platform to take better decisions. On the other hand, in UMCourt we are researching novel approaches to negotiation and mediation, in line with the concept of intelligent 
environments. In that sense, our objective is to develop environments able to provide the conflict resolution platform with important information including the level of stress of the parties, the conflict style or even the emotional state. In this section we focus on the issue of the compilation of important knowledge. The actual architecture of UMCourt will not be depicted here as that has already been done in previous work $[20,21]$. The dynamic nature of the conflict resolution will be detailed in the following sections.

\subsection{Building Important Knowledge}

There is a whole set of knowledge that parties in conflict may use in order to take better and more informed decisions, as addressed before. Under the framework of the TIARAC project we are developing methods for compiling this kind of knowledge. Considering the BATNA and the WATNA, its estimation is usually well defined in the rulings of The Law, in the form of norms. These norms can be implemented in rule-based systems, which efficiently determine, according to the characteristics of the case under evaluation, the legal boundaries of the outcome. As an example of the drawing on of such rules, it is presented below a listing of Def_Rule 396, an abstract description of the procedures that allow the computation of the BATNA and WATNA for the Portuguese Labor Law, as it is stated in Decree of Law (DL) 7/2009 (Portuguese Laws). This simplified rule considers only the case in which a worker ends the contract with a just cause.

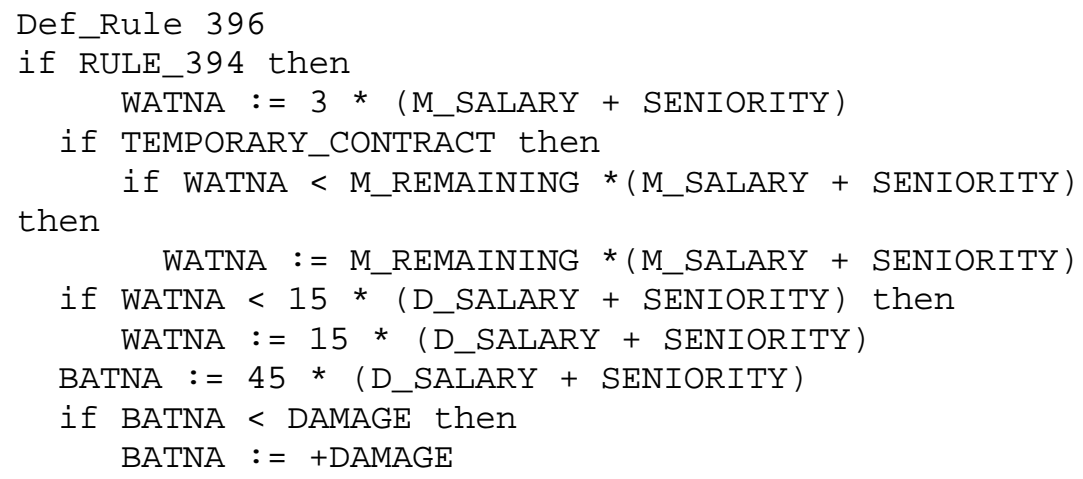

Considering the MLATNA, a slightly different approach is being followed. In fact, in order to determine the most likely outcome, the system needs to analyze past cases in a given context. In that sense, to determine the MLATNA, UMCourt follows a Case-based approach. In a few words, the most similar cases are selected and sorted according to their degree of similarity. The region of the MLATNA will be defined by the most similar cases as, in the legal domain, one may assume that similar cases have similar outcomes, pointing out where an outcome for a case with given characteristics is likely.

As stated before, it is also important for parties to have access to past cases, so that 
they can analyze them and gain a better understanding about the domain of the problem. In that sense, the framework is able to present the litigant parties with cases that may be relevant, according to their degree of similarity. Besides that, for each selected case, the system also computes the utility of its outcome according to the characteristics of the current case, i.e., the users may acknowledge how much they would gain or lose if the outcome of their cases were the same. Indeed, similar cases may have different outcomes, depending on (in the case of Labor Law) attributes such as worker seniority, wage, and existence or not of extra hours of work not yet paid, among others. In order to be able to compute the utility of the solutions of other cases with respect to the new case, they are structured so that they may be applied to different cases in order to compute its outcomes.

At the end, all this information is presented in a graphical form to the user. Figure 1 depicts a prototype of this interface. Looking at this representation, the user is able to acknowledge the distance between the BATNA and the WATNA (allowing him/her to assess the risk of his/her decisions), to analyze the maximum and minimum utility and similarity values or analyze the similarity versus the utility [22].

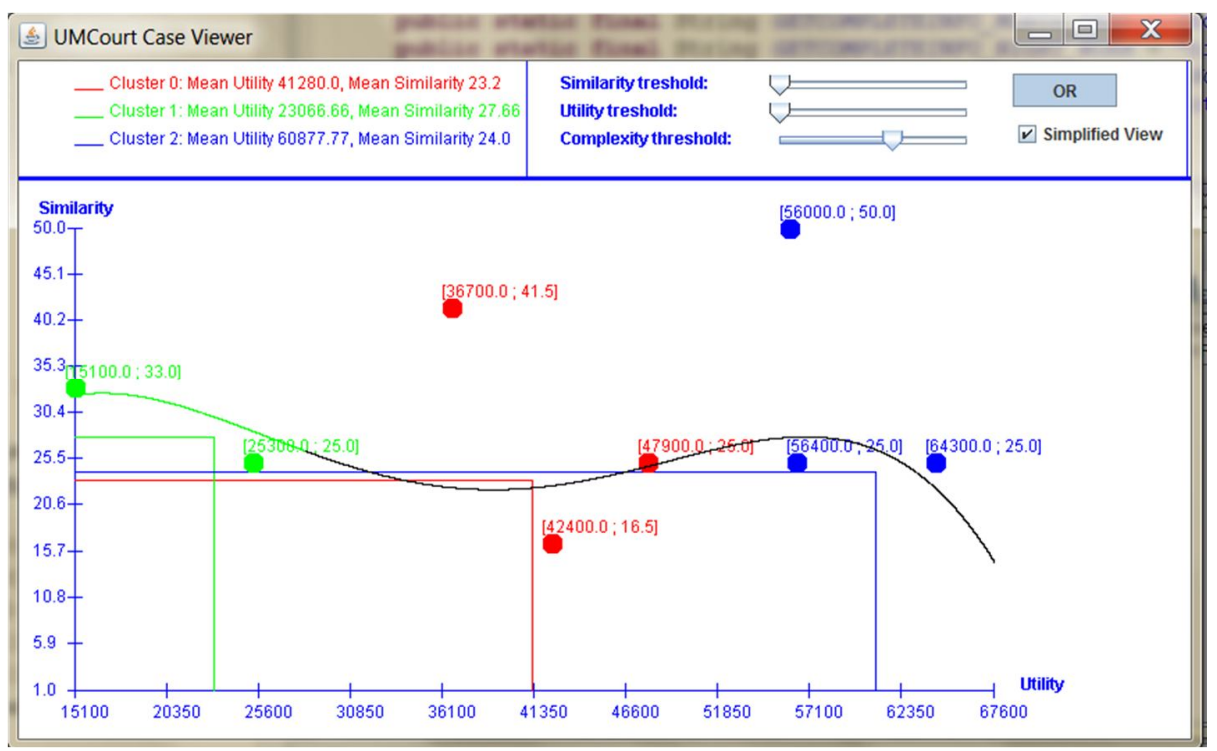

Fig. 1. The prototype of the interface depicting the important knowledge compiled for a party. According to the complexity threshold slider, only a smaller number of cases (colored circles) are presented. The user can click on a case to see its details. The linear regression shows the MLATNA in green. Different colors represent different information clusters.

\section{Interpretation of Conflict Styles}

It is reasonable to state that in a negotiated process, the most significant factor is the behavior of the parties. In that sense, by knowing in advance how each party behaves, it is possible to draw the best strategy in order to increase the possibility of achieving 
a successful outcome. The behavior of the parties can essentially be determined in two different ways: by questioning the parties and by analyzing their behavior. The first provides information before the start of the process although it is easy to lie and fake a behavior. Moreover, when we are under stressful situations (as a negotiated process potentially is), we tend to behave differently than we usually do. The second one takes some time to gather enough information to be accurate although it reflects the behavior of the parties in a more reliable way.

In this work, we focus on the interpretation of conflict styles during the negotiated process, by analyzing the behavior of the parties in real time. In that sense, we analyze the actions of the parties in each stage of the negotiation, in which a party may ignore, accept, refuse, exit, reply with a new proposal or reply with a counterproposal. Moreover, we also take into consideration the nature of the solutions proposed (e.g. is a party being too greedy?, is a party being realistic?). The approach proposed consists in analyzing these factors together with the BATNA and the WATNA of each party as well as the ZOPA, in order to classify the behavior of each party.

Basically, during the negotiation process, parties make successive proposals and counterproposals in order to achieve a mutually agreeable solution. We can thus analyze the proposals of each party in each round according to the actions of the parties and a space defined by the BATNA and WATNA of each party (Figure 2). In each round, each action of a party will contribute to the overall characterization of this conflict style. Thus, the personal conflict style that is computed for each party in each round is a result of all the previous interactions. Two main scenarios are possible: the party ignores the proposal or the party answers to the proposal.

If a party, upon receiving a proposal for a solution, simply ignores it, he is not satisfying his interests nor the ones of the other party. In such a scenario, the conflict style evidenced is the Avoiding one.

If the party makes a proposal or a counterproposal, he is cooperating on the process. However, the nature of the proposal must be analyzed, namely in terms of its utility for each party. If the utility of the proposal is higher than the BATNA of the other party, he is clearly showing a Competing style as he is trying to maximize his own gain, probably in an unrealistically way, completely disregarding the other party. On the other hand, if the utility of the proposal is lower than the WATNA of the other party, he is neglecting his own gain or even maximizing the gain of the other party. In such a scenario, it is reasonable to state that the party is evidencing an Accommodating behavior.

When the utility of the proposal falls within the range of the ZOPA, it indicates that the party is being reasonable and try to propose a settlement in which both parties will not win everything but will not lose everything either. In such a scenario, the conflict style is determined according to the distance to the meant point of the ZOPA, defined in (1).

$$
\beta=\left(\frac{Z O P A_{M I N}+Z O P A_{M A X}}{2}\right)
$$

Two additional points can be defined that will allow to classify the remaining conflict styles. These points, depicted in (2) and (3), allow defining additional intervals to classify the personal conflict styles. 


$$
\begin{aligned}
& \alpha=\left(Z O P A_{M I N}+\frac{\beta-Z O P A_{M I N}}{2}\right)=\left(\frac{Z O P A_{M I N}+\beta}{2}\right) \\
& \gamma=\left(Z O P A_{M A X}-\frac{Z O P A_{M A X}-\beta}{2}\right)=\left(\frac{Z O P A_{M A X}+\beta}{2}\right)
\end{aligned}
$$

Namely, when the utility of a proposal falls within the range $[\alpha, \gamma]$, it means that the proposing party is negotiating in an intermediary points of the ZOPA. That is, the party is trying to work out compromise that implies a loss from both parties. In such a scenario, it may be said that the party is evidencing a Compromising behavior.

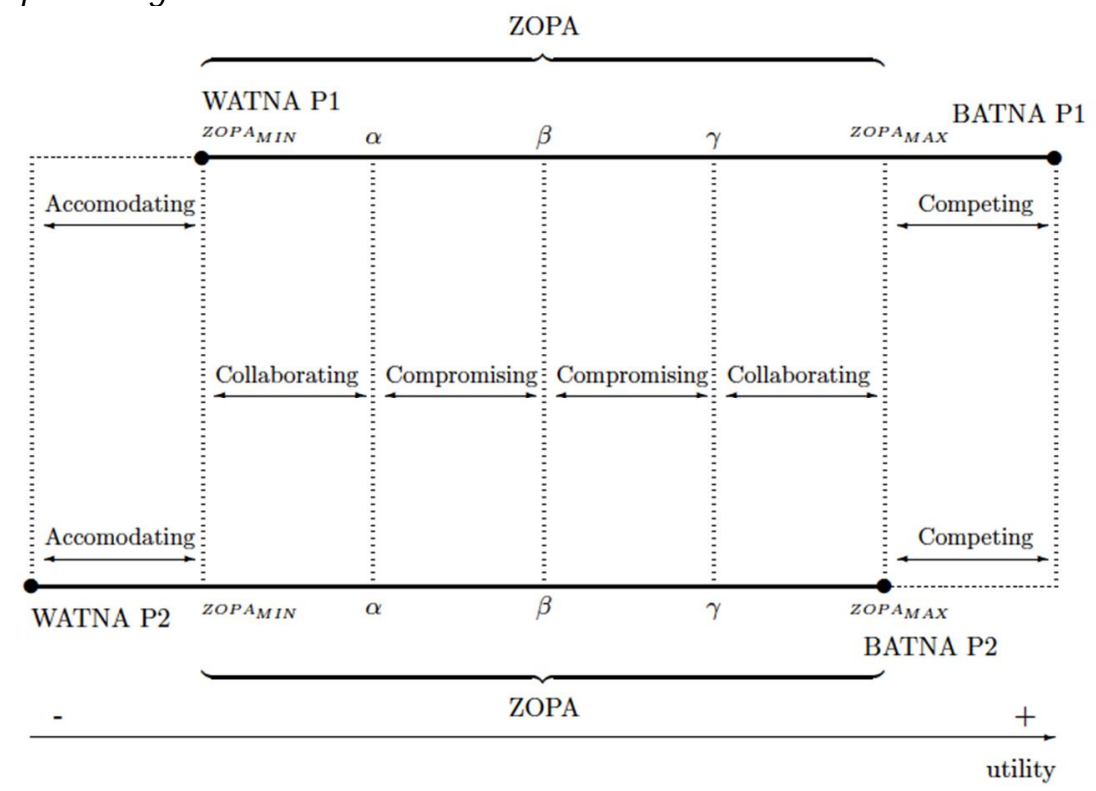

Fig. 2. The space that defines the personal conflict styles in function of the utility of the proposals and the values of the BATNA, BATNA and ZOPA.

On the other hand, if the value of the utility belongs to the range defined by $\left[Z O P A_{M I N}, \alpha[\cup] \gamma, Z O P A_{M A X}\right]$, the party is proposing a solution that is closer to the limits of the ZOPA. This may mean that although the party is trying to work out a mutually agreeable solution, he may be trying to explore the weaknesses of the opposing party trying to force him to accept a given solution. Under this scenario, the conflict style of the party may be defined as Collaborating.

However, we are aware that we do not make use of a single conflict style at a time. In that sense, we propose a more accurate approach in which a main conflict style is inferred, together with a trend style, meaning that a party shows a given style with a possible tendency towards another one. The following notation is used to denote a main conflict style with a trend to a secondary one: Main $\rightarrow$ secondary. .

Let $\varphi$ be the value of the utility of a proposal. The following personal conflict styles are defined: 
Collaborating $\rightarrow$ Accomodating
Collaborating $\rightarrow$ Compromising
Compromising $\rightarrow$ Collaborating-Accomodating
Compromising $\rightarrow$ Collaborating-Competing
Collaborating $\rightarrow$ Compromising

Collaborating $\rightarrow$ Collaborating-Competing

$$
\begin{aligned}
& \text { if } \varphi \in\left[Z O P A_{M I N}, \frac{Z O P A_{M I N}+\alpha}{2}[\right. \\
& \text { if } \varphi \in\left[\frac{Z O P A_{M I N}+\alpha}{2}, \alpha[\right. \\
& \text { if } \varphi \in[\alpha, \beta[ \\
& \text { if } \varphi \in[\beta, \gamma[ \\
& \text { if } \varphi \in\left[\gamma, \frac{Z O P A_{M A X}+\gamma}{2}[\right. \\
& \text { if } \varphi \in\left[\frac{Z O P A_{M A X}+\gamma}{2}, Z O P A_{M A X}\right]
\end{aligned}
$$

By determining the personal conflict style of each party in each round, it is possible to analyze its evolution throughout the conflict resolution process (Figure 3). This will allow the framework to determine the best moments to adapt strategies, as will be seen in the following section.

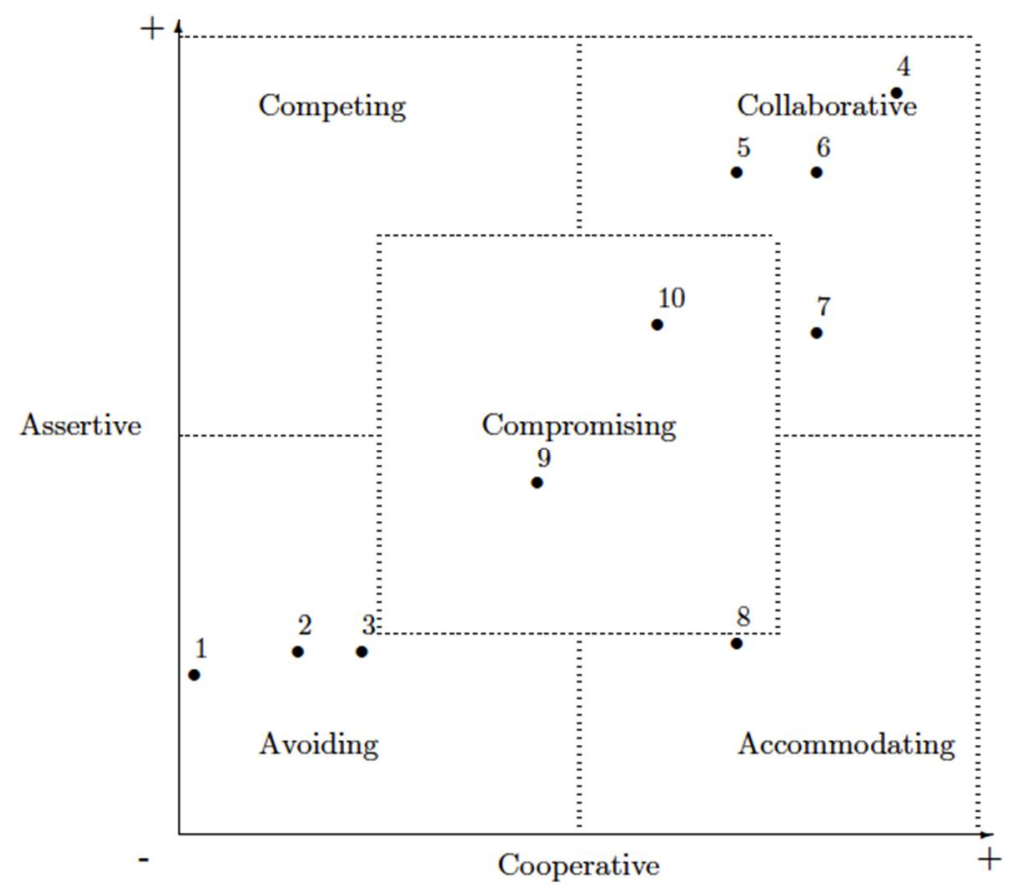

Fig. 3. The evolution of the conflict style of a party during 10 rounds of the conflict resolution process.

\section{A Dynamic Conflict Resolution Model}

In line with the recent trend of Intelligent Environments in which computer systems gradually merge into the environment [3], we aim to develop dynamic conflict 
resolution methods to be used in the context of a proactive environment. In fact, conflict resolution methods that are run by human experts are generally dynamic as experts have the ability to understand changes in the context of interaction (e.g. a party is getting stressed, a party does not like the current state of affairs) and change the strategy before it is too late (e.g. by making a pause in the process). However, the problem is that under ODR settings, such context information is not available as parties are, generally, "hidden" behind a web interface while they are studying and making proposals for negotiation. This, we believe, is the main problem with current ODR platforms. In that sense, we aim at a new vision on the ODR issue, in line with the concept of Ambient Intelligence. Thus, in this new approach, parties are not simply interacting with web forms. Instead, parties use ODR tools in the context of an intelligent environment that can provide the conflict resolution platform with important context information like the level of stress, the conflict style or even the emotional state.

With this information, the conflict resolution model can dynamically adjust to changes in the context of interaction. As an example, if the conflict resolution platform detects that one of the parties is getting stressed, it may temporarily pause the process or assume a mediator role in which all the communication goes through it and no direct communication between the parties takes place. When the party calms down, the platform may once again allow direct contact between the parties.

However, given the scope of this paper, we are more interested on the role of personal conflict styles in these dynamic models. As said before, each person tends to use more some conflict styles than others, either because of their personality or of past experiences. Moreover, it is common for parties to change the conflict style during the conflict resolution process, according to how it is developing. As an example, it is common for a party to exhibit an avoiding behavior at the outset of the process and then start being more cooperative as confidence on the process grows. Moreover, it is also common for parties to start by being competitive and with high expectations and then, as the process develops and they gain a more realistic view that includes the desires and rights of the others, tend to be more compromising. Evidently the opposite may also happen, i.e., parties that start fully cooperative but that don't like the way that the process is going and start moving towards a more uncooperative style.

The work developed in this context focus on detecting this kind of changes in order to adapt strategies in real time. Basically this adds a new step to the conflict resolution model of UMCourt, making it a dynamic conflict resolution model (Figure 4). This model starts by building all the important knowledge mentioned before, which will be important for parties to develop realistic views about their problem. Then, the platform builds a strategy. In a first iteration, this consists in selecting a group of possible outcomes that will sequentially be suggested to the users. In order to build this first strategy, the platform only takes into consideration the group of similar cases that was selected. Then, the process advances to the actual conflict resolution, either by means of negotiation or mediation.

During this phase, the platform constantly receives information from the environment concerning the personal conflict styles, determined as described above. Whenever the platform detects that a significant change is occurring, an adaptation in the strategy takes place. At this moment, adapting strategies consists in changing the list of outcomes to be proposed to the parties. In order to do it, one very important 
issue is taken into consideration: the utility of each outcome for each party. The utility of an outcome depicts, as stated before, how good each outcome is for a given party. Thus, the platform looks at the utility of the outcomes of the similar cases and changes the order by which outcomes will be proposed according to the state of the parties. Let us take as example a setting with two parties, in which one party is consistently exhibiting a collaborative behavior while the other is moving from a collaborative to an avoiding one. This may be indicative that the second party is not appreciating the way that the process is going. In that sense, in order to prevent that party from abandoning the process, the system will suggest an outcome whose utility is better for that party than the previous one. This is expected to increase the satisfaction of the party, maintaining him interested in continuing with the process and probably taking him back to a collaborative style.

We are however aware that the information about the personal conflict styles alone is not enough. In that sense, our work now focuses on additional sources of information that the platform can use to adapt strategies. Namely, we are considering the use of information about the keystroke intensity of the parties in order to determine the level of stress as well as some linguistic features. Information about stress is very important, namely to assess the level of escalation of the parties, depicting when the process should be interrupted before emotions running high. We are also considering several ways of determining the emotional state of the parties as this information is of ultimate importance to determine how each issue affects each party. Namely, we are considering non-invasive methods that include image and speech analysis.

With the combination of all this important information we will be able to develop context-aware conflict resolution models that take advantage of technological tools without however losing the richness of face-to-face interaction. This way, we expect to achieve more efficient conflict resolution mechanisms, able to achieve more mutually satisfactory outcomes.

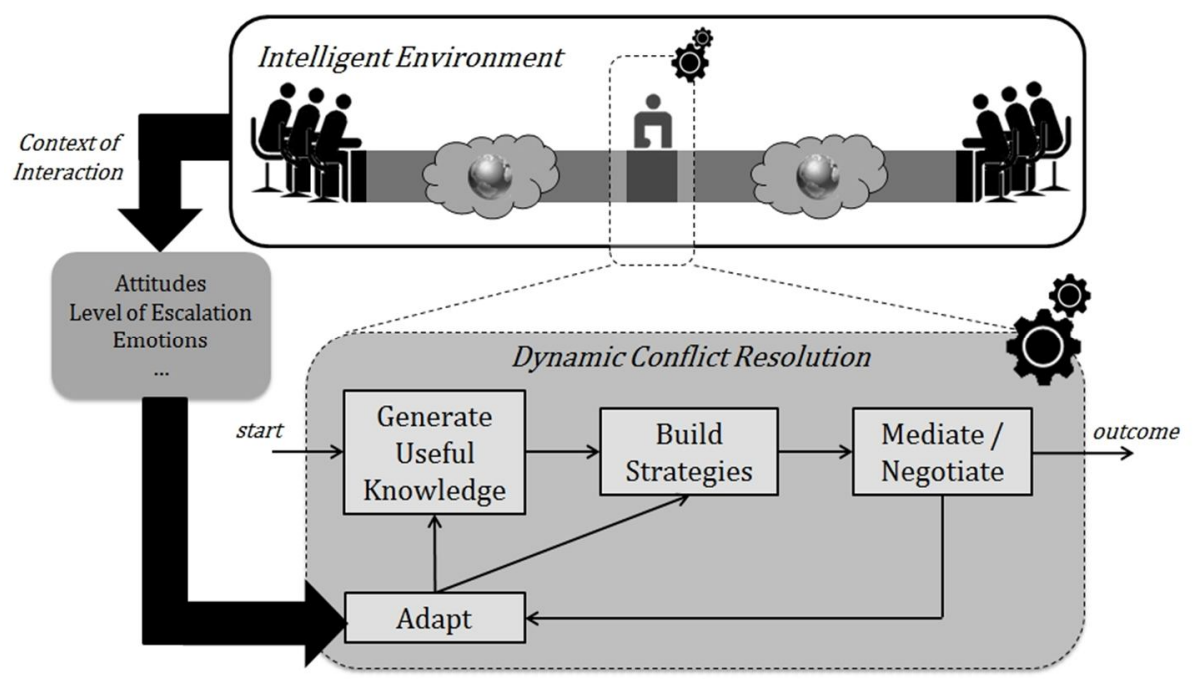

Fig. 4.High level view of the dynamic conflict resolution model presented. 


\section{Conclusions}

Current approaches on Online Dispute Resolution are heavily based on technology, as it would be expected. However, this tends to leave aside some important advantages of traditional human-centered approaches. Specifically, the ability of human mediators to deal with context information such as the emotional state of the parties or their personal conflict resolution styles is completely disregarded. This results in conflict resolution platforms that are insensible, unable to perceive the fears and desires of the parties in conflict. In order to reach the so-called second generation ODR, we believe it is mandatory to consider not only all the important context information but also methods that can make use of it in order to more accurately understand the parties and achieve outcomes that are more satisfactory.

In that sense we presented in this paper a methodology for determining the personal conflict styles of the parties, by analyzing their behavior during a negotiated or mediated conflict resolution process. All this is done in a non-intrusive way. Merging this with additional context information such as the levels of stress or even the emotional state, will allow the development of conflict resolution methods that are able to adapt, in real time, to significant changes in the context of interaction. This approach, in line with the vision of Ambient Intelligence, will bring significant advantages for the field of conflict resolution in the sense that it can empower cold and insensitive processes with context-aware abilities usually associated to human experts.

Acknowledgments. The work described in this paper is included in TIARAC Telematics and Artificial Intelligence in Alternative Conflict Resolution Project (PTDC/JUR/71354/2006), which is a research project supported by FCT (Science \& Technology Foundation), Portugal. The work of Davide Carneiro is also supported by a doctoral grant by FCT (SFRH/BD/64890/2009).

\section{References}

1. Lewin, K.: Resolving social conflicts: Field theory in social science. American Psychological Association, ISBN 1557984158 (1997)

2. Pitt, J., Ramirez-Cano, D., Kamara, L., Neville, B.: Alternative Dispute Resolution in Virtual Organizations. In: Artikis, A., O'Hare, G., Stathis, K., Vouros G. (Eds.): Engineering Societies in the Agents World VIII. Lecture Notes in Artificial Intelligence, Vol. 4995. Springer-Verlag, 72--89 (2008)

3. Aarts E., Grotenhuis F., Ambient Intelligence 2.0: Towards Synergetic Prosperity, Journal of Ambient Intelligence and Smart Environments 3, 3-11, IOS Press (2011)

4. Katsch, E., Rifkin, J.: Online dispute resolution - resolving conflicts in cyberspace. JosseyBass Wiley Company, San Francisco (2001)

5. Lewicki, R.J., Barry, B., Saunders, D.M., Minton, J.W.: Negotiation, 4th ed., McGrawHill/Irwin (2003)

6. Goldberg, S.B., Sander, F.E., Rogers, N., Cole, S.R.: Dispute Resolution: Negotiation, Mediation and Other Processes, Aspen Publishers, New York (2003)

7. Raiffa, H.: The Art and Science of Negotiation. Harvard University Press (2002)

8. Walton, P.R.E., McKersie, R.B.: A behavioral theory of labor negotiations. McGraw-Hill 
(1965)

9. Brown, H., Marriott, A: ADR Principles and Practice. Sweet and Maxwell (1999)

10.Bennett, S. C. Arbitration: essential concepts. ALM Publishing (2002)

11.Peruginelli, G., Chiti, G.: Artificial Intelligence in Online Dispute Resolution. Proceedings of the Workshop on the law of electronic agents - LEA (2002)

12.Lodder, A., Thiessen, E.: The role of artificial intelligence in online dispute resolution. In: Workshop on Online Dispute Resolution at the International Conference on Artificial Intelligence and Law, Edinburgh, UK (2003)

13.Notini, J.: Effective Alternatives Analysis in Mediation: "BATNA/WATNA" Analysis Demystified, (http://www.mediate.com/articles/notini1.cfm) (2005) <last accessed May, 2011>

14.Klaming, L., Van Veenen, J., Leenes, R.: I want the opposite of what you want: summary of a study on the reduction of fixed-pie perceptions in online negotiations. "Expanding the horizons of ODR", Proceedings of the 5th International Workshop on Online Dispute Resolution (ODR Workshop'08), Firenze, Italy, 84--94 (2004)

15.De Vries BR., Leenes, R., Zeleznikow, J.: Fundamentals of providing negotiation support online: the need for developing BATNAs. Proceedings of the Second International ODR Workshop, Tilburg, Wolf Legal Publishers, pp. 59--67. (2005)

16.Fisher, R., Ury, W.: Getting To Yes: Negotiating Agreement Without Giving In. Boston: Houghton Mifflin (1981)

17.Steenbergen, W.: Rationalizing Dispute Resolution: From best alternative to the most likely one, in Proceedings 3rd ODR workshop, Brussels (2005)

18.Raiffa, H.: The art and science of negotiation: how to resolve conflicts and get the best out of bargaining, Cambridge, The Belknap Press of Harvard University Press (1982)

19.Thomas, K., Kilmann, R.: Conflict and Conflict Management. Available at http://www.kilmann.com/conflict.html (1974) <last accessed May, 2011>

20 Carneiro D., Novais P., Costa R., Neves J., Developing Intelligent Environments with OSGi and JADE, Artificial Intelligence in Theory and Practice III, Bramer M. (Ed), SpringerVerlag, Series: IFIP International Federation for Information Processing, ISBN 978-3-64215285-6, pp 174-183 (2010)

21.Costa, N., Carneiro, D., Novais, P., Barbieri, D., Andrade, F.: An Advice System for Consumer's Law Disputes, in Enterprise Information Systems $\left(12^{\text {th }}\right.$ International Conference, ICEIS 2010, Revised Selected Papers), Joaquim Filipe and José Cordeiro (Eds), Springer: Lecture Notes in Business Information Processing, Volume 73, ISBN: 978-3-64219802-1, 237-248 (2011)

22.Andrade F., Novais P., Carneiro D., Zeleznikow J., Neves J., Using BATNAs and WATNAs in Online Dispute Resolution, in New Frontiers in Artificial Intelligence, Kumiyo Nakakoji, Yohei Murakami and Eric McCready (Eds), (JSAI-isAI 2009 Workshops, LENLS, JURISIN, KCSD, LLLL, Tokyo, Japan, 2009, Revised Selected Papers), Springer - LNAI 6284, ISBN 978-3-642-14887-3, pp 5-18 (2010) 